\title{
Tipología de la prensa femenina. Una propuesta de clasificación
}

\author{
María Isabel MENÉNDEZ MenÉNDEZ \\ Universidad de Burgos \\ mimenendez@ubu.es
}

Recibido: 09/04/2012

Aceptado: 18/12/2012

\begin{abstract}
Resumen
Las revistas femeninas han recibido poca atención científica, hasta el punto de que no suelen formar parte de los estudios sobre prensa. Junto al desinterés académico, la complejidad de un segmento editorial compuesto por un conjunto heterogéneo de títulos explica que todavía no exista una tipología estable que ofrezca un punto de partida a nuevas investigaciones. La materia plantea enormes retos para la categorización que el presente artículo pretende aliviar, proponiendo una sistematización que se ha enriquecido de los esfuerzos previos realizados desde la literatura especializada, por lo que también se incluye un sucinto recorrido por la bibliografía de referencia.
\end{abstract}

Palabras clave: prensa femenina, prensa especializada, revistas para mujeres, género, feminismo

\section{Typology of the Women's Press. A Proposal for Classification}

\begin{abstract}
Women's magazines have received little scientific attention, to the extent that they are not usually included in the research about press. Together with this lack of academic interest, the complexity of an editorial branch composed by a myriad of heterogeneous titles explains the lack of a stable typology that could serve as a starting point for the new research. The issue constitutes an enormous challenge for categorization that this paper will try to tackle by proposing a systematization enriched by efforts made in previous scholarship, which is also revised briefly here.
\end{abstract}

Keywords: Women's press, specialized press, women's magazines, gender, feminism.

\section{Referencia normalizada}

MENÉNDEZ MENÉNDEZ, María Isabel (2013): “Tipología de la prensa femenina. Una propuesta de clasificación”. Estudios sobre el mensaje periodístico. Vol. 19, Núm. 1, págs.: 191-206. Madrid, Servicio de Publicaciones de la Universidad Complutense.

Sumario: 1. Introducción. 2. La prensa femenina y las dificultades conceptuales. 3. Contribuciones teóricas desde el punto de vista ideológico. 4. Contribuciones teóricas desde el punto de vista formal. 5. Categorías en discusión: la prensa del corazón y la prensa feminista. 6. Conclusiones: hacia una clasificación de la prensa femenina. 7. Referencias bibliográficas.

\section{Introducción}

Las revistas dirigidas a mujeres (conocidas habitualmente como prensa femenina) han despertado poco interés como objeto de investigación, a pesar de su larga historia y de su innegable relevancia en el mercado editorial. Para la experta Danièle Bussy-Génevois su estudio es importante ya que es imposible estudiar la prensa y su historia sin abordar la existencia de revistas olvidadas o ignoradas pero que, no obstante, permiten acceder a información sobre la historia de la civilización, los hábitos, las costumbres o la vida cotidiana (Bussy-Génevois, 1996: 99-109). Sin embargo, estas publicaciones siguen hoy recibiendo poca atención científica, a pesar de que su análisis únicamente puede aportar, sumar y no restar, a los trabajos ya existentes relati- 
vos a los diferentes medios de comunicación, sus audiencias y su relación con el entorno. El desinterés académico por estos títulos mediáticos es quizá la explicación a la escasez de esfuerzos teóricos y metodológicos sobre la materia, algo que impide acceder a una definición precisa y a una categorización satisfactoria de este tipo de publicaciones. La prensa femenina ni siquiera suele formar parte de las antologías sobre prensa o los estudios canónicos sobre historia de los medios de comunicación (de ahí que tampoco forme parte de los currículos en las facultades de comunicación). Ello a pesar de que, como advertía Carl N. Warren en su momento, "las mujeres financian la prensa". Según este autor, ninguna publicación podía tener éxito si no sabía atraer a las mujeres (Warren, 1975: 379).

Además de la definición de las revistas como prensa femenina, que es de por sí una cuestión compleja y a la que apenas se han dedicado energías intelectuales, el establecimiento de una tipología apropiada y clara es probablemente uno de los retos todavía poco abordados desde la Academia. El presente artículo intenta paliar esta laguna de investigación ofreciendo una construcción propia que, no obstante, se ha enriquecido de los esfuerzos anteriores que otros textos han desarrollado. En este sentido, y como explica García de León, "detectar una carencia o describir y documentar una laguna bibliográfica constituyen per se resultados consistentes de investigación" (García de León, 2011: 69), enunciación desde la que argumentamos la pertinencia y oportunidad del presente trabajo.

\section{La prensa femenina y las dificultades conceptuales}

La expresión revistas femeninas, contiene dos términos en los que es necesario detenerse, tal y como recuerda uno de los últimos trabajos teóricos que se han publicado (Menéndez, 2009: 279). En primer lugar, el vocablo revista, que ha sido definido exhaustivamente y que se puede resumir en que son publicaciones seriadas, cuya aparición responde a intervalos de tiempo regulares y cuya fecha y numeración son correlativas. Además, se caracterizan porque no responden a la estricta novedad, ofreciendo una información más contextual y atraen a un público segmentado mediante elementos singulares, como la calidad del papel, los gráficos o los contenidos especializados (Ortega, 1997: 91). La expresión contiene, en segundo lugar, el término femeninas, cuya definición es compleja por el propio adjetivo que acompaña el enunciado. La definición de estos títulos como prensa femenina es muy habitual en la literatura académica y, a pesar de su vaguedad, suele aceptarse el concepto como punto de partida, sin reparar en lo confuso del propio sintagma:

La denominación misma de prensa femenina es vaga y se presta a confusión. Cuando se habla de literatura femenina, ¿no entendemos, en efecto, la literatura escrita por las mujeres? Cuando se trata de prensa femenina, se entiende generalmente las publicaciones dirigidas a mujeres, sean o no editadas por mujeres. (Sullerot, 1963: 69)

$\mathrm{Si}$ en materia de prensa, las fronteras son muy fluidas y toda definición es arbitraria, la cuestión sigue siendo difícil porque es complicado delimitar cuándo una publicación está dirigida a las mujeres. Habitualmente, es el criterio del público el que se utiliza para segmentar pero, si bien es esta una variable mayoritariamente admitida, también es insuficiente para una definición correcta (Figueras, 2005: 52). Suele acep- 
tarse que las revistas femeninas son aquellas que tienen como principales destinatarias a las mujeres pero se trata de una enunciación que no soluciona la ambigüedad porque ¿qué es lo femenino?

Más delimitada conceptualmente es la propuesta de Hinojosa, quien parte de la diferencia entre revista femenina y revista dirigida a mujeres. Las primeras serían aquellas de temática femenina (dedicadas al espacio reproductivo y a la feminidad) mientras que las segundas serían las que establecen a las mujeres como público objetivo y cuyos intereses pueden ser diferentes, como sería el caso de las publicaciones feministas (Hinojosa, 2005: 96). Tras incorporar esta aportación, la definición más reciente y probablemente más completa es la que sostiene que:

Revistas dirigidas a mujeres son aquellas publicaciones seriadas especializadas, de periodicidad variable y superior a una semana; distribuidas bajo distintas fórmulas de difusión (de pago, gratuitas o mixtas); cuyo público objetivo es explícita o implícitamente de sexo femenino, ya sea adulto o juvenil (circunstancia verificable a través de sus editoriales, la temática, sus inserciones publicitarias y los estilos de comunicación); cuya audiencia está mayoritariamente integrada por mujeres (entre el 60 y el 75 por ciento como mínimo) y que, en función de sus características formales, pueden formar parte o no de las publicaciones de alta gama. En cuanto a los contenidos, son títulos que abordan, bajo diferentes tipologías y con objetivos distintos, los aspectos relacionados con la socialización diferencial femenina y el espacio reproductivo y, sólo en algunos casos, la discriminación de género y/o la emancipación de las mujeres. (Menéndez, 2009: 294)

En el aspecto metodológico, la segunda dificultad que presentan las publicaciones dirigidas a mujeres se deriva de su heterogeneidad. El problema es consecuencia de la existencia de un curioso caleidoscopio de revistas de variada naturaleza que obliga a realizar un esfuerzo de sistematización todavía sin resolver. La codificación es difícil y por ello la categorización sobrevive dentro de cierta ambigüedad teórica. En este sentido ya advertía Casasús, cuando aseguraba que la prensa femenina constituía una categoría difusa pues, según este autor, constituye una "tipología hemerográfica de tal amplitud que abarca desde publicaciones de alta costura hasta prensa del corazón" (Casasús, 1998: 271). Danièle Bussy-Génevois, por su parte, aseguraba que la situación de la prensa femenina era de aspecto polimorfo (Bussy-Génevois, 1996: 100). Cierto es que los principales nombres de la teoría de la comunicación no han dedicado esfuerzo alguno a esta dificultad y a día de hoy sigue sin existir una clasificación satisfactoria.

En las líneas siguientes se aportará una nueva contribución a la materia, sin pretender por ello concluir una disquisición teórica que sigue abierta y que sin duda seguirá proporcionando interesantes aportaciones académicas. Como se ha avanzado, han existido múltiples intentos de clasificar la prensa femenina aunque todavía no se ha alcanzado el consenso pues existe una evidente dificultad metodológica para delimitar este objeto de estudio y para realizar una clasificación óptima, probablemente porque es difícil ponerse de acuerdo sobre qué significa ser mujer, qué es lo femenino o cuáles son los intereses de las mujeres (Ganzábal, 2004: 481). Repasemos, en primer lugar, las aportaciones que ha brindado la literatura especializada en las últimas décadas. 


\section{Contribuciones teóricas desde el punto de vista ideológico}

Una clasificación muy conocida es la que, a finales de los setenta del siglo XX, propuso Anne-Marie Dardigna para las publicaciones femeninas galas. Según esta autora, se puede establecer que existen cuatro tipos de prensa femenina: 1) categoría intermedia o destinada a mujeres de clases modestas. Son publicaciones que transmiten la idea de una mujer dulce y relacionada con el entorno doméstico; 2) revistas de patrones, es decir, las que incluyen figurines para confección y consejos de costura; 3) prensa del corazón; 4) publicaciones dirigidas a la clase media y alta (Dardigna, 1979: 24). La clasificación, si bien es utilizada con cierta profusión, presenta demasiada indeterminación y también es discutida por algunas autoras, sobre todo por su inclusión de la prensa del corazón entre estas publicaciones ya que muchos textos no consideran que esos títulos sean prensa femenina (en esta cuestión nos detendremos más adelante). Además, en sus categorías no se incluyen algunas segmentaciones que son sin duda necesarias ni tampoco algunas modalidades específicas de este tipo de discurso.

Una categorización mucho más general pero que, sin embargo, puede establecer un punto de partida para una sistematización más clara, es la que proponían las también francesas Samra-Martine Bonvoisin y Michèle Maignien una década más tarde. Estas autoras dividían la prensa femenina en dos grandes bloques: 1) por estilos y formas de vida; y 2) por grupos de edad y categorías socioprofesionales (Bonvoisin y Maignien, 1986: 38-40). Como veremos más adelante, esta clasificación se acerca a la última aportación elaborada por Juana Gallego, autora que ha escrito abundantemente sobre la materia que nos ocupa.

En cuanto a la literatura publicada en España, tal y como pone de manifiesto Mònica Figueras, la mayoría de investigaciones han adscrito las revistas dirigidas a mujeres, con distintos matices, en tres bloques: revistas sobre "temas de mujeres" o femeninas; revistas ideológicas (políticas y religiosas) y revistas feministas (Figueras, 2005: 52). La segunda de estas categorías, frecuente en la literatura científica se debe, como es obvio, a la importancia de estos soportes en el largo periodo franquista, aunque en la actualidad no tienen presencia. Así, Adolfo Perinat y M. ${ }^{\mathrm{a}}$ Isabel Marrades, a partir de una primera clasificación que organizaba las publicaciones en prensa alineada y prensa no alineada, distinguieron cuatro entradas: femeninas sin ideología política o social, cuyo discurso se acercaba al eterno femenino; religiosas o católicas; político-regionalistas y feministas-emancipadoras (Perinat y Marrades, 1980: 110). ${ }^{1}$

\footnotetext{
1 Según este texto, el eterno femenino es un modelo de mujer ideal que responde a la representación social creada por el pensamiento patriarcal, casi siempre a partir de la memoria colectiva y sus mitos: Beatriz, Dulcinea, Julieta... modelos que se repiten en la literatura y el arte; en artículos, poesías y novelas; mujeres que se identifican con flores, ángeles, estrellas o vírgenes y que proponen una lectura de mujer mítica que, sin embargo, es el prototipo de la feminidad. Se apoya en una concreta imagen corporal (belleza como dulzura y juventud) y en la naturaleza buena y pura del alma. En la expresión corporal, el eterno femenino define la belleza juvenil, el uso de técnicas de coquetería o las normas estéticas sobre peinado, adorno, depilación, moda y otras cuestiones de lo físico. Pero, además, el alma femenina debe ser un principio de perfección: bondad y pureza, como antítesis de las mujeres malas.
} 
Marta Selva e Isabel Segura las clasificaron en cinco grupos: modas, patronaje y métodos de bordar, familiares o domésticas, relativas a la condición de las mujeres, religiosas y de higiene (Selva y Segura, 1984). Otro texto, el de Francesc Espinet, las dividió entre generales, de modas, católicas, feministas, políticas, infantiles, ginecológicas y otras -sobre cine, arte, pediatría, deportes, prostitución, etc. (Espinet, 1989: 50). Mercedes Roig, por su parte, organizó las revistas publicadas tras la llegada de la Democracia según tres rúbricas: 1) revistas femeninas para militantes, es decir, las de orientación feminista; 2) revistas femeninas y familiares promovidas por organizaciones religiosas; y 3) revistas femeninas comerciales (Roig, 1989: 408).

Otra obra muy citada, publicada en 1990 y firmada por la ya mencionada Juana Gallego, proponía una clasificación en función de los objetivos de la publicación: 1) revistas femeninas de información general; 2) revistas especializadas de divulgación y orientación; y 3) revistas especializadas de servicios (Gallego, 1990: 50). La primera de estas categorías, la más genuina en la prensa femenina según esta autora, sería aquella que ofrece una visión global de lo que es y representa ser mujer en la sociedad. Para ello, se distingue del resto de publicaciones a través de elementos formales y discursivos: por su materia, por su estilo de comunicación y por la portada y el nombre. Las revistas especializadas de divulgación y orientación, por su parte, son aquellas que no ofrecen una visión global sino que se especializan en un terreno concreto del ámbito doméstico. Son guías que dan orientaciones para determinadas facetas de la vida. Por último, las revistas especializadas de servicios abordan un tema concreto, a partir del cual gira toda la revista. Este tipo de publicaciones siempre han incidido en un espíritu práctico, por lo que otros textos las consideran como prensa de servicio. Son revistas que han experimentado su propia evolución, en torno al concepto calidad de vida, en el que ahora destaca el interés por la salud o la decoración.

Gallego revisaría su propio ordenamiento tiempo después, profundizando en la definición teórica elaborada en su primera obra. Para ella, hay que empezar por preguntarse porqué existe una prensa femenina y no una prensa masculina, tal y como han planteado otros textos, de ahí que sugiera que la prensa femenina deje de denominarse como tal para ser considerada como prensa de 'estilo de vida'. ${ }^{2}$ La clasificación que esta autora propone en 2008 es la siguiente: 1) revistas de estilo de vida (antes femeninas de información general) que incluye tanto las dirigidas a mujeres como las dirigidas a hombres, un segmento de la edición que ha experimentado su propio crecimiento en fechas recientes; 2) revistas del corazón; y 3) prensa del hogar (antes especializadas de divulgación y servicios) que se subdivide en revistas de moda, de salud y bienestar, de gastronomía, de labores y de decoración (Gallego, 2008: 173). Esta nueva organización separa, como ya había hecho en su anterior trabajo, la prensa del corazón de la prensa femenina.

La tipificación que ofrece Manuel Ángel Vázquez agrupa la prensa femenina en función de la posición ideológica, lo que excluye muchas cabeceras de orden práctico. Las entradas propuestas por este autor son tres: 1) revistas que refuerzan los valores feme-

2 Para profundizar en el concepto prensa femenina vs. prensa masculina, véase MENÉNDEZ, 2009: 277-297. 
ninos estereotipados; 2) revistas que introducen nuevos valores; y 3) revistas feministas que abogan por la liberación radical de las mujeres (Vázquez, 1999: 99; énfasis aña-

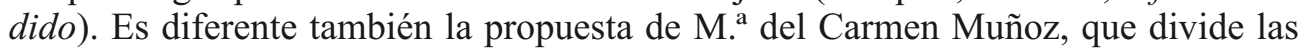
publicaciones estudiadas en su análisis en tres categorías: 1) revistas femeninas y familiares, cuyos contenidos orientan y entretienen sobre los temas que supuestamente les interesan a las mujeres (moda, cocina, criaturas, etc.); 2) revistas de información gráfica, donde se incluyen las revistas de evasión o del corazón. Entre ellas, la autora señala el carácter político de algunas cabeceras emblemáticas, como ;Hola! y sus numerosos reportajes sobre Franco y sus relaciones internacionales; y 3) revistas publicadas por diferentes organismos, básicamente las instituciones franquistas que existían en el periodo analizado. Hay que destacar que esta autora utilizó para su investigación revistas publicadas hasta los años setenta del siglo XX (Muñoz, 2002: 221).

También ha dedicado esfuerzos a la materia Fernando Cabello, quien organiza los contenidos dirigidos a las mujeres en cinco bloques: 1) decoración; 2) gastronomía; 3) personas famosas; 4) para la mujer; y 5) labores y patrones (Cabello, 1999: 79). Aunque reconoce la dificultad para definir este segmento, dada la variedad de títulos, para él la enunciación de revista femenina debe partir del hecho de que se dirijan y sean leídas mayoritariamente por mujeres, que traten de moda y belleza y que no aborden contenidos políticos o ideológicos (Cabello, 1999: 135). Esta afirmación es francamente discutible, ya que calificar lo femenino de no ideológico o no político no deja de ser una lectura androcéntrica y quizá paternalista pero, en todo caso, el autor observa que existen muchos criterios distintos para ordenar el heterogéneo conjunto de revistas dirigidas a las mujeres: según los contenidos, según la edad de las lectoras, según el diseño y la calidad formal, etc.

En relación a esta cuestión, señala que las revistas, en función de la calidad formal del producto (tipo de papel, fotografías, tamaño, etc.) pueden ser revistas de alta gama, de gama media o de gama baja. Sin embargo, plantea este autor que también se puede optar por una clasificación mixta que divida las revistas en: 1) revistas de alta gama; 2) revistas prácticas; y 3) revistas juveniles (Cabello, 1999: 156). En esta aportación encontramos una nueva rúbrica para definir la prensa, que no es otra que las características formales que, para múltiples textos, son igual de importantes que los contenidos, incluso para algunas investigaciones se trata de la dimensión más relevante. A esta cuestión dedicaremos el epígrafe siguiente, con especial atención a la definición de revista de alta gama.

\section{Contribuciones teóricas desde el punto de vista formal}

El concepto alta gama aparece con frecuencia en los textos que han abordado la prensa femenina y, de hecho, es la que utilizan las investigaciones académicas más recientes. Sin embargo, no es una expresión unívoca. Así por ejemplo, un trabajo reciente escribe que la prensa de alta gama, está conformada por publicaciones periódicas centradas sobre todo en moda y belleza y va dirigida a la mujer, principal consumidor [sic.] del mercado de revistas mensuales. Se trata de uno de los pocos productos de la cultura de masas española escrito por, para y sobre mujeres, abarca temas definidos culturalmente como femeninos y propaga ideales de feminidad y de belleza. Su contenido 
editorial también presta atención a temas que no suelen encontrarse fácilmente en otras expresiones periodísticas como, por ejemplo, la independencia económica o la plenitud sexual de la mujer. Puesto que se trata de medios de masas, gozan tanto de relevancia política como de cierta autoridad frente a la audiencia femenina, sobre la cual se les puede suponer por lo tanto influencia a priori; la lectora encuentra en la revista de moda y belleza una especie de cómplice que se dirige específicamente a ella en un intimista tono de camaradería. (Torres, 2007: 213-214)

La definición de esta autora revela muchos de los problemas detectados en la literatura especializada, comenzando por la utilización de una locución no delimitada conceptualmente, tal y como ocurre en otros trabajos contemporáneos, como el de Jiménez y Gómez en el que, sin definir qué es prensa femenina, se acepta dicha definición como punto de partida, cuestión abordada al inicio de este trabajo (Jiménez y Gómez, 2006: 245). Asimismo, la propuesta de Torres presenta cierta confusión entre contenido, objetivos, efectos, aspecto formal y estilo discursivo que no contribuye a la claridad expositiva.

Como revelan Pilar Pérez y María Garrido, la denominación alta gama es una "autodefinición proporcionada y emitida por las propias revistas" (Pérez y Garrido, 2006: 102). Es un autoconcepto que ayuda a esos títulos a situarse en un lugar destacado de la industria editorial, diferenciándose del resto de publicaciones, aquellas que son más populares o más asequibles y que los estudios académicos admiten para definir:

un segmento concreto dentro de las revistas femeninas y atribuir características específicas del mismo como mayor calidad formal (mejor papel, diseño y fotografia), mayor nivel socioeconómico de las lectoras, publicidad de productos o servicios exclusivos, etc. (Pérez y Garrido, 2006: 102)

Se considera revista de alta gama aquella que incluye publicidad de marcas vinculadas a la alta costura o la tradición cosmética arraigada en el sector; estas revistas no contienen otra publicidad que la de aquellos productos que indican prestigio o estatus social. La enunciación alta gama establece un paralelismo con la expresión alta costura, a la que pocas mujeres pueden acceder. Revista de alta gama es sinónimo de calidad, de perfumes y cosméticos elitistas y de altos precios (Pérez y Garrido, 2006: 103). Las propias editoriales aplican criterios distintos para establecer si una revista es de alta gama o no, unas veces atendiendo a que las cabeceras apuesten por el lujo y la sofisticación, otras a través de los requisitos formales que avalan la calidad material del producto. En definitiva, no existe un criterio sólido o inequívoco para sostener que una revista sea de alta gama o no (Garrido, 2007: 44). Lo que sí parece demostrado es que las lectoras no necesitan pertenecer al perfil ideal pues únicamente un $20 \%$ de las lectoras de estos títulos pertenecen a una clase socioeconómica alta. Es decir, hay lectoras de clase media que están dispuestas a invertir en productos de calidad o en marcas elitistas. Como explica María Garrido, en la definición de alta gama interviene el poder adquisitivo pero también el querer adquisitivo, es decir, la aspiración o el deseo de formar parte de un universo de referencia (Garrido, 2007: 45).

Según Hinojosa, existen otros criterios para establecer la clasificación. Así, las revistas de alta gama serían aquellas que eligen modelos cotizadas para ilustrar su portada, que utilizan papel satinado de alta calidad y fotografías artísticas para ilustrar los 
reportajes de moda, que incorporan tipografía y diseño innovadores (Hinojosa, 2005: 103). Por otro lado, el precio de la publicación puede ayudar a establecer esta confusa pero tan utilizada definición: las revistas así consideradas son más caras que las demás, y otra variable significativa es la aparición en sus páginas de algún personaje celebrity o celeb. Es éste un personaje admirado e inaccesible, generalmente situado por encima o al margen del resto del mundo debido a su resonancia social. Entre ellos se encuentran algunos actores y actrices de relevancia internacional, top models, grandes fortunas, nombres propios de las empresas de moda o cosmética, personas relacionadas con la alta costura, etc. La prensa de alta gama desestima a los personajes populares que aparecen en la prensa del corazón, solo le interesan la celebrity, a quien nunca se paga por aparecer en sus páginas. Es decir, no existen exclusivas, una realidad que sí forma parte de la prensa del corazón. Salir en los títulos de alta gama es un elemento de prestigio por sí mismo (Pérez y Garrido, 2006: 125; Garrido, 2007: 49). Por tanto, el tipo de personaje es también un elemento diferenciador de las revistas de alta gama, es decir, en Vogue no aparecen las mismas personas que en Diez minutos y tampoco tiene la misma trascendencia hacerlo en un lugar u otro.

La indeterminación que tiene el concepto alta gama también se deriva de que, a pesar de ser un autoconcepto, no es suficiente con la voluntad editorial para que una publicación sea considerada como tal. Encontramos un ejemplo de esta afirmación en Garrido, quien demostró cómo una publicación que se autodenominó de alta gama y así lo hizo explícito en su primer editorial, no era contemplada como tal por ninguna de las personas expertas a las que se consultó al respecto (Garrido, 2007: 44).

Sintetizando lo anterior, hay que enfatizar que, pese a la oscuridad de un concepto profusamente empleado, la definición de revista de alta gama es ambigua y remite a la coincidencia de una serie de características: desde el punto de vista objetivo, ofrecen mayor gramaje del papel, maquetación y diseño elegante, encuadernación de calidad, impresión y calidad fotográfica excelentes o reportajes muy cuidados y elaborados. Desde el enfoque subjetivo, son títulos que apuestan por el lujo (aunque sea de forma aspiracional) y que coinciden en la variable sociodemográfica a quien se dirigen: individuo urbano, de poder adquisitivo medio-alto, con preferencias más bien elitistas de consumo y estilos de vida y, generalmente, mujeres (pero también varones) profesionales de edad superior a los treinta años ${ }^{3}$. En estas revistas de gama alta existe una gran tipología de materias: decoración, viajes, motor, estilo de vida... aunque son muy numerosas estas últimas, concretamente las dedicadas a moda y belleza, es decir, aquellas que siempre se han denominado tradicionalmente como $\mathrm{fe}$ meninas (Garrido, 2007: 73-74).

Utilizando la rúbrica de gama para clasificar las publicaciones, Juan Plaza profundiza en la clasificación mixta de Cabello, definiendo las categorías y aportando ejemplos. Las revistas de alta gama serían aquellas dedicadas sobre todo a la moda y la belleza, dejando a un lado los asuntos domésticos o abordándolos someramente. Estas revistas presentan una mayor calidad de impresión y un precio más elevado;

3 Según el Estudio General de Medios (EGM), el perfil de lectoras de revistas de alta gama zestá mayoritariamente integrado por mujeres entre 35 y 44 años, de clase media. 
suelen dirigirse a profesionales económicamente independientes de edades entre $25 \mathrm{y}$ 45 años, con un nivel social medio-alto. Algunas cabeceras de este tipo son Telva, Elle, Marie Claire, Vogue o Woman. Las revistas prácticas, sin embargo, tienen una calidad formal que las sitúa en una gama media. En sus contenidos incluyen información de servicios y contenidos útiles sobre moda, belleza o cocina. Son revistas más baratas y se dirigen, fundamentalmente, a amas de casa y trabajadoras de clase media. Títulos de este segmento serían Mía, Belleza y moda, Prima o Clara. Por último, las revistas juveniles son las que segmentan su público objetivo por edad; relativamente nuevas en España, diferencian la audiencia joven del resto pues prácticamente no existen otras segmentaciones. Su público se establece, entonces, entre los 14 y los 19 años de edad, con un porcentaje de lectoras de sexo femenino en torno al $90 \%$, y cuyos contenidos abordan los ya conocidos sobre belleza y moda, pero añadiendo otros como música, amor y sexualidad, amistad y personas famosas. Sin embargo, en la actualidad se está abriendo el abanico, ampliando los grupos de edad hasta la preadolescencia (11-12 años). Publicaciones que pertenecen a esta categoría serían Ragazza o You (Plaza, 2005: 97-98).

Otra novedad la propone María Garrido, autora que también se apoya en Cabello como punto de partida. Su clasificación añade la categoría público, que luego subdivide por género y por edad pues, a su juicio, la clasificación de las revistas femeninas es una especialización demográfica por sexo y, las revistas de alta gama en concreto, son una subespecialización basada en el público (Garrido, 2007: 29).

\section{Categorías en discusión: la prensa del corazón y la prensa feminista}

Las revistas del corazón, aunque suelen formar parte de las clasificaciones sobre prensa femenina, según escribía Gallego en su obra de 1990, no son publicaciones femeninas pero sí dirigidas a las mujeres (110). Esta autora consideraba entonces que una publicación es femenina si aborda las materias de la socialización diferencial, esto es, la información sobre el espacio privado, de ahí que argumente que las revistas del corazón no deben clasificarse como femeninas. Recordemos que los contenidos de dichos títulos abordan la vida sentimental de las personas famosas y no la temática del espacio privado. Serían una modalidad de prensa dirigida a una audiencia femenina pero no una revista femenina. Sobre esta cuestión han trabajado otros textos.

Así, el texto de M. José Recoder también incide en esta consideración. Tras señalar que se trata de una prensa que no orienta ni informa (variables que serían esenciales a la prensa femenina), enfatiza que a partir de ella no es posible reconstruir las costumbres de una época pues, al enfocar su contenido en la vida de la gente famosa, realiza una selección de sujetos distintos, superiores, por lo que nunca es referente de la sociedad a la que se dirige (Recoder, 1982). Mar de Fontcuberta argumenta de forma similar y explica que la prensa del corazón no tiene los mismos objetivos que la prensa femenina (orientar e instruir) sino que se limita a construir una ficción más cercana a la literatura, a través de personajes de ensueño (Fontcuberta, 1990: 59). También Gaudino-Fallegger propone que las revistas del corazón no se consideren femeninas porque no sólo gozan de una audiencia mixta, sino que se ocupan de temas específicos de la alta sociedad, la aristocracia y el espectáculo (Gaudino-Fallegger, 1999: 301). 
Encarnación Pérez, por su parte, sostiene que las revistas del corazón no sólo se distinguen de las femeninas en que no comparten sus objetivos sino que, para ella, las primeras son el "baluarte de los roles tradicionales" mientras que las segundas son el "baluarte de la mujer liberada y moderna", aserción contradictoria que más tarde matiza al afirmar que se trata únicamente de una "versión modernizada del mismo lenguaje inmovilista" (Pérez, 2002: web).

Esta difícil cuestión de adscribir o no la prensa gráfica o del corazón a la prensa femenina ha sido analizada en profundidad en la investigación más reciente, cuyo trabajo de campo incluía diversas cabeceras (Menéndez, 2010: 623-625). Concluyó que la prensa del corazón se diferencia de la prensa femenina, en primer lugar, porque incluye en su agenda temática algunos temas de la prensa de referencia, rompiendo con el clima favorable a la ensoñación y el hedonismo que es la seña de identidad de toda la prensa para mujeres. Asimismo, las características discursivas que la literatura científica ha identificado como emblema identitario de la prensa femenina se recogen en la prensa gráfica sólo en parte pues, mayoritariamente, ésta utiliza la enunciación informativa, sin implicación de la destinataria. Tampoco en la morfología sigue la tendencia mayoritaria de los otros títulos porque en la prensa gráfica no existe el mismo tipo de portada, sus tapas no están protagonizadas por la imagen del eterno femenino que es exclusiva de las otras revistas. Sin embargo, sí incorpora cierto lenguaje personal, al hablar en femenino, lo que implica que asume que su audiencia está integrada por mujeres (de hecho ellas son mayoría según los estudios de audiencia) y, en ocasiones, incorporando los recursos habituales en la prensa femenina para favorecer la intimidad o la empatía con las lectoras. También aborda las temáticas diferenciales de la prensa especializada, aunque sólo en parte, pues sus espacios más numerosos están dedicados a informar de la vida de las personas célebres -claro que incorporando las valoraciones genéricas. Finalmente, y al no pertenecer al segmento de alta gama, la publicidad que incluyen estas revistas es dual: por un lado, las firmas de alta cosmética, perfumería y moda, que también aparecen en las otras revistas y, junto a ellas, una publicidad que podría considerarse más doméstica y que nunca aparece en revistas de otras categorías, como productos de alimentación, de limpieza o de hogar.

Por último, y en relación a la prensa feminista, Juana Gallego la ubica en una categoría aparte pues considera que su discurso es opuesto al de las revistas femeninas. Sobre el estado actual de estas publicaciones resalta que existe prensa feminista en todos los países de nuestra órbita cultural, excepto en España, donde estos títulos desaparecieron con la llegada de la Democracia (Gallego, 1990: 135). María Ganzábal también incide en que la mayoría de países que cuentan con medios de comunicación social publican un mínimo de cabeceras feministas, aunque no ocurre así en España, donde algunos de sus contenidos forman parte de la prensa femenina. En Alemania existen dos docenas de revistas y en Estados Unidos de América se cuentan por centenares, algunas con cifras de difusión que permiten catalogarlas como prensa de masas, como una de las más antiguas, $M S$, editada en Nueva York. En Francia, $F$ fue el primer periódico feminista, de gran éxito comercial y cuya tirada, siete años más tarde de su nacimiento en 1978, había alcanzado el medio millón de ejemplares (Ganzábal, 2004: 153). Para Ganzábal, algunos asuntos de la agenda feminista han entrado 
a formar parte de las revistas femeninas contemporáneas, como la violencia de género e incluso la desmitificación de la belleza, pero reconoce que son contenidos poco relevantes en dichas publicaciones, cuyo contenido global está bastante alejado de lo feminista. Al hilo de lo expuesto, conviene recordar la advertencia de Dardigna que, en su momento, escribía: "Desconfiemos cuando la prensa llamada femenina se pone al día del feminismo" (1979: 108). Para ella, dicha estrategia no era más que una forma de manipular a su audiencia, a través de temas cercanos y/o sensibles.

En consonancia con lo anterior y para contribuir al debate teórico, Hinojosa recuerda que suelen usarse como sinónimos las expresiones prensa femenina y prensa para mujeres pues la mayoría de textos no diferencian entre las publicaciones de temática femenina y las que establecen como público objetivo a las mujeres, que pueden obedecer a otro tipo de intereses, como por ejemplo las publicaciones feministas (Hinojosa, 2005: 96). En realidad, el presente texto propone que la segunda expresión incluye a la primera; es decir, las revistas femeninas siempre se dirigen, de forma mayoritaria, a las mujeres, mientras que las revistas dirigidas a una audiencia femenina, como pueden ser las feministas, aunque también se dirigen a mujeres, no necesariamente incluyen la temática que se ha dado en llamar femenina.

\section{Conclusiones: hacia una clasificación de la prensa femenina}

La aportación que se ofrece en las líneas siguientes constituye un nuevo intento de sistematización, que se nutre de las aportaciones de todos los textos que han dedicado esfuerzos a la materia, y que probablemente podrá ser revisada o complementada, teniendo en cuenta el espectacular dinamismo del sector que estamos abordando. Sigue siendo necesario este esfuerzo teórico ya que la clasificación mixta que suelen utilizar los trabajos más recientes es poco satisfactoria, entre otras razones porque pone al mismo nivel elementos formales, por ejemplo la calidad del papel, con otros de contenido, como la temática relacionada con la socialización diferencial, cuando ambas categorías no son en absoluto equivalentes, afectando la primera a una dimensión económica, pues es la que utilizan las empresas de publicidad; y la segunda a aspectos sociológicos, es decir, la relación entre temática femenina y roles de género, por una parte, y con la construcción de identidad por otra.

Por otro lado, en este tipo de sistematización se confunden variables objetivas como el estilo de comunicación o la edad del público destinatario que muchas veces se recoge explícitamente y que siempre se puede deducir a partir de la publicidad-con elementos subjetivos, como la función legitimadora/otorgadora de estatus. Además, las revistas de alta gama no son una categoría en sí mismas desde el punto de vista del análisis de revistas dirigidas a mujeres, quizás sí lo sean para la investigación publicitaria. Son únicamente una cualidad de una categoría, que comparten solo algunos de los títulos y que ha sido definida por las empresas publicitarias, lo que sitúa este aspecto por encima de los contenidos, claramente más importantes. Es decir, desde un punto de vista sociológico y/o mediático, no debería ser más relevante el carácter formal de la revista que los contenidos que incluye. Por otra parte, la tipificación mixta hace incompatibles cabeceras híbridas entre, por ejemplo, la alta gama y el público objetivo juvenil o la información práctica. 
Ello quiere decir que el trabajo de clasificación exige un esfuerzo de refinamiento que sin duda no es fácil. Por consiguiente, y dejando abierta la reflexión a futuras aportaciones, planteamos que las revistas destinadas a mujeres (y no prensa femenina) se pueden clasificar en una tipología como la que se expone en la Tabla 1. Esta propuesta se apoya, fundamentalmente, en la aportación más reciente de Juana Gallego, mencionada más arriba, y que recoge otras consideraciones y reflexiones aparecidas en un trabajo anterior al suyo pero que no llegaba a profundizar desde el punto de vista conceptual (Menéndez, 2006).

Esta clasificación no incluye todas las variables que definen una revista de masas, únicamente se recogen aquellas que se han considerado significativas para su estudio como soporte especializado (en este caso en función de la audiencia). Y tampoco puede resolver cuestiones tradicionales de este tipo de medios, como la existencia de formatos híbridos que no pueden adscribirse a una sola categoría. Asimismo, es evidente que, al contener únicamente las revistas femeninas, no aparecen otras que podrían formar parte de este cuadro si tuviera el objetivo de abarcar toda la edición de revistas. Ello explica que no aparezcan las revistas masculinas o cuya temática está relacionada con la socialización diferencial de los varones, ni tampoco otras cuestiones sobre la edición en general.

Tabla 1. Tipología de la prensa dirigida a mujeres en España en la actualidad. Elaboración propia.

\begin{tabular}{|c|c|c|}
\hline \multicolumn{3}{|c|}{ PRENSA DE MASAS DIRIGIDA A MUJERES EN ESPAÑA EN LA ACTUALIDAD } \\
\hline \multirow{9}{*}{ ELEMENTOS } & \multicolumn{2}{|c|}{ TIPOLOGÍA } \\
\hline & \multicolumn{2}{|c|}{$\begin{array}{l}\text { Revistas especializadas en estilo de vida (antes } \\
\text { femeninas): temática relacionada con la socialización } \\
\text { diferencial femenina en relación con sus protagonistas, } \\
\text { las mujeres }\end{array}$} \\
\hline & \multirow{4}{*}{$\begin{array}{l}\text { Revistas especializadas de } \\
\text { hogar (abordan } \\
\text { aspectos del dintos } \\
\text { reproductivo) }\end{array}$} & $\begin{array}{l}\text { Confección, patrones y } \\
\text { labores }\end{array}$ \\
\hline & & Salud y bienestar \\
\hline & & Gastronomía \\
\hline & & Decoración \\
\hline & \multicolumn{2}{|c|}{$\begin{array}{l}\text { Revistas prácticas o híbridas estilo de vida-hogar } \\
\text { (incluyen temáticas de las dos categorías) }\end{array}$} \\
\hline & \multicolumn{2}{|c|}{$\begin{array}{l}\text { Revistas de información gráfica, evasión o del corazón } \\
\text { (tratan de la vida sentimental de las personas famosas) }\end{array}$} \\
\hline & \multicolumn{2}{|c|}{$\begin{array}{l}\text { Revistas feministas (temática sobre las mujeres en el } \\
\text { espacio público, emancipación femenina e igualdad) }\end{array}$} \\
\hline \multirow{5}{*}{ PERIODICIDAD } & \multicolumn{2}{|c|}{ Semanal } \\
\hline & \multicolumn{2}{|l|}{ Quincenal } \\
\hline & \multicolumn{2}{|l|}{ Mensual } \\
\hline & \multicolumn{2}{|l|}{ Trimestral } \\
\hline & \multicolumn{2}{|l|}{ Otros formatos } \\
\hline \multirow{3}{*}{ CALIDAD FORMAL } & \multicolumn{2}{|l|}{ Alta gama } \\
\hline & \multicolumn{2}{|l|}{ Gama media } \\
\hline & \multicolumn{2}{|l|}{ Gama baja } \\
\hline \multirow{2}{*}{$\begin{array}{l}\text { EDAD DEL PÚBLICO } \\
\text { OBJETIVO }\end{array}$} & \multicolumn{2}{|l|}{ Juvenil } \\
\hline & \multicolumn{2}{|l|}{ Mujeres adultas } \\
\hline \multirow{3}{*}{ DIFUSIÓN } & \multicolumn{2}{|l|}{ De pago } \\
\hline & \multicolumn{2}{|l|}{ Gratuitas } \\
\hline & \multicolumn{2}{|l|}{ Combinadas } \\
\hline
\end{tabular}


Como se puede comprobar en la tabla, las revistas dirigidas a mujeres en España se dividen en cinco categorías: 1) la prensa especializada en estilo de vida; 2) la prensa especializada de hogar; 3) la prensa práctica o híbrida estilo de vida-hogar; 4) la prensa de información gráfica, evasión o del corazón; y 5) la prensa feminista. Probablemente la aportación más significativa, además de denominar de otra forma a las revistas femeninas en sintonía con la propuesta de Gallego, es la división entre las primeras, las que abordan los temas de la socialización diferencial desde el punto de vista de sus agentes (las mujeres), contenidos que versan sobre belleza, psicología, educación sentimental, criaturas, relaciones con los demás, etc.; y las segundas, dedicadas de forma especializada a algún aspecto del espacio reproductivo, es decir, el hogar, y no tanto a las protagonistas de dicho espacio: decoración de la casa, técnicas de cocina, arreglo de jardines, confección de indumentaria, etc.

La primera de estas especialidades compete a las revistas denominadas habitualmente como femeninas, que abordan las temáticas y protagonistas de la socialización diferencial de las mujeres (aunque pueden incluir algún contenido de las de hogar de forma minoritaria) y en ella se encuentran cabeceras como Marie Claire, Cosmopolitan, Vogue, Elle o Telva. La segunda especialidad tiene que ver con aquellos títulos cuyo contenido recoge de forma exhaustiva y experta temas que se relacionan con el espacio reproductivo, es decir, con el hogar. Se subdividen en cuatro tipos: 1) confección, patrones y labores; 2) salud y bienestar; 3) gastronomía; y 4) decoración. Aquí encontramos cabeceras como Labores del hogar, Nueva Burda, Psychologies, Comer y beber o Casa y jardín. La tercera posibilidad, las revistas prácticas o híbridas de las dos anteriores, son títulos que recogen de forma más o menos equilibrada (desde el punto de vista cuantitativo) los contenidos de las primeras y de las segundas, generalmente con vocación práctica y carácter divulgativo, como las revistas Mía o Clara, y también los suplementos que la mayoría de diarios de información general ofrecen en la actualidad a sus lectoras el fin de semana, tales como Yo Dona o Mujer Hoy. En la prensa de información gráfica, de evasión o del corazón se encuentran las cabeceras clásicas de este sector como ;Hola!, Diez minutos, Semana o Lecturas. Por último encontramos la prensa feminista que, como se ha expuesto anteriormente, en la actualidad es inexistente como prensa de masas y/o comercial en España. Su existencia se reduce a las publicaciones no comerciales del movimiento asociativo o de las instituciones de igualdad.

Los títulos que responden todos estos epígrafes, ordenados en función de los contenidos, se cruzan con el resto de categorías significativas: difusión, calidad formal, público objetivo al que se dirigen y periodicidad. Es necesario contemplar que algunos títulos responden a una categoría híbrida, por lo que no es fácil su ubicación y dependerá del contexto de análisis del trabajo de campo. Algunos ejemplos de la clasificación propuesta son los siguientes:

- Labores del hogar, revista especializada de hogar (subcategoría: confección, patrones y labores), de pago, de gama media, de periodicidad mensual y dirigida a mujeres adultas.

- Mía, revista práctica, de pago, de gama media, de periodicidad semanal y dirigida a mujeres adultas. 
- Bravo por ti, revista especializada en estilo de vida, de pago, de gama baja, de periodicidad quincenal y dirigida a mujeres jóvenes.

- Diez minutos, revista de evasión, combinada, de gama baja, de periodicidad semanal y dirigida a mujeres adultas.

- Vogue, revista especializada en estilo de vida, de pago, de alta gama, de periodicidad mensual y dirigida a mujeres adultas.

- Meridiam, revista feminista, de gama media, gratuita, de periodicidad trimestral y dirigida a mujeres adultas.

Hay que remarcar, no obstante, que en los estudios de audiencia que habitualmente se manejan en España (fundamentalmente los de la OJD, Oficina de Justificación de la Difusión, y el EGM, Estudio General de Medios) la mayoría de las publicaciones anteriores se encuadran bajo una única rúbrica: 'revistas femeninas', que forman parte de la categoría 'revistas especializadas'4. Como puede concluirse, sigue siendo un reto clasificar las heterogéneas publicaciones que hoy se destinan a un público objetivo femenino. Es un reto intelectual que permite ampliar un campo de análisis poco explorado en la investigación académica y desde el que se abren fértiles caminos para nuevas investigaciones. Mientras llegan planteamientos nuevos que sin duda enriquecerán las aportaciones ya existentes, desde estas líneas se sugiere una posible sistematización para quienes deseen explorar el interesante campo de la prensa dirigida a mujeres.

\section{Referencias bibliográficas}

BONVOISIN, Samra-Martine y MAIGNIEN, Michèle (1986): La presse féminine. Paris, Presses Universitaires de France.

BUSSY-GÉNEVOIS, Danièle (1996): “Aproximación metodológica a la prensa para mujeres en España (1931-1936)", en GARITAONANDIA, Carmelo y TUÑÓN DE LARA, Manuel (coords.): La prensa de los siglos XIX y XX. Metodología, ideología e información. Aspectos económicos y tecnológicos: I Encuentro de la Historia de la Prensa. Bilbao, Universidad del País Vasco, pp. 99-109.

CABELLO, Fernando (1999): El mercado de las revistas en España. Concentración informativa. Barcelona, Ariel.

CASASÚS, Josep María (1998): Ideología y análisis de los medios de comunicación. Barcelona, CIMS.

DARDIGNA, Anne-Marie (1979): La presse féminine. Fonction idéologique. Paris, François Maspero.

4 Algunas revistas que pueden considerarse como 'femeninas' o de 'estilo de vida', están clasificadas en otras subcategorías de las revistas especializadas como por ejemplo: Embarazo sano en 'familiares'; Barbie en 'infantiles'; Bravo por ti en 'musicales'; Psychologies en 'salud'; Labores del hogar en 'labores y patrones' o Casa y jardín en 'decoración'. 
ESPINET, Francesc (1989): "El segundo frente informativo: revistas y prensa especializada", en TIMOTEO, Jesús y otros: Historia de los medios de comunicación en España. Periodismo, imagen y publicidad (1900-1990). Barcelona, Ariel, pp. 50-70.

FIGUERAS, Mónica (2005): Premsa Juvenil femenina i identitat corporal. Tesis doctoral. Barcelona, Universidad Pompeu Fabra.

FONTCUBERTA, Mar de (1990): "El discurso de la prensa del corazón”. Anàlisi, no 13, Universidad Autónoma de Barcelona, pp. 53-72.

GALLEGO, Juana (2008): "La prensa femenina: una cala de difícil abordaje", en FERNÁNDEZ, Juan José (coord.): Prensa especializada actual. Doce calas. Madrid, McGraw Hill, pp. 131-175.

GALLEGO, Juana (1990): Mujeres de papel. De ;Hola! a Vogue. La prensa femenina en la actualidad. Barcelona, Icaria.

GANZÁBAL, María (2004): La revista femenina española en los 90. Análisis hemerográfico de seis revistas femeninas actuales, Woman, Elle, Marie Claire, Telva, Dunia y Cosmopolitan. Tesis doctoral. Leioa, Universidad del País Vasco.

GARCÍA DE LEÓN, María Antonia (2011): Cabeza morderna/corazón patriarcal (un diagnóstico social de género). Barcelona, Anthropos.

GARRIDO, María (2007): Los rasgos temáticos y de estilo propios del periodismo de servicio en las revistas femeninas de alta gama. Tesis doctoral. Salamanca, Universidad Pontificia de Salamanca.

GAUDINO-FALLEGGER, Livia (1999): "Notas sobre la sintaxis de los titulares de las revistas femeninas", en GARRIDO, Joaquín C. (ed.): La lengua y los medios de comunicación. Volumen I. Madrid, Universidad Complutense de Madrid, pp. 298-310.

HINOJOSA, María Paz (2005): Análisis de las modalidades de la enunciación en los textos de moda y belleza de la prensa femenina de alta gama. Tesis doctoral. Murcia, Universidad de Murcia.

JIMÉNEZ, Gloria y GÓMEZ, Domingo (2006): "El uso de la pintura en la publicidad de revistas femeninas en España. Análisis de la publicidad que usa pintura en la revista Vogue", Trípodos, no extra, Universidad Blanquerna Ramon Llull, pp. 245257.

MENÉNDEZ, María Isabel (2009): “Aproximación teórica al concepto de prensa femenina", Comunicación y Sociedad, vol. XXII, nº 2 diciembre, Universidad de Navarra, pp. 277-297.

MENÉNDEZ, María Isabel (2006): El zapato de Cenicienta. El cuento de hadas del discurso mediático. Oviedo, Trabe.

MENÉNDEZ, María Isabel (2010): Imágenes de las mujeres en los medios de comunicación. Las revistas femeninas como escenarios de corporeidad (1976-2006). Tomo I. Tesis doctoral. Madrid, UNED. 
MUÑOZ, M. ${ }^{a}$ del Carmen (2002): Mujer mitica, mujeres reales. Las revistas femeninas en España, 1955-1970. Tesis doctoral. Madrid, Universidad Complutense de Madrid.

ORTEGA, Enrique (1997): La comunicación publicitaria. Madrid, Pirámide.

PÉREZ, Encarnación (2002): "La revista femenina: falso emblema de la mujer liberada", en Revista Latina de Comunicación Social, $n^{\circ}$ 49, Universidad de La Laguna:http://www.ull.es/publicaciones/latina/2002/latina49abril/4911 salicio.htm [fecha de consulta: 16 de marzo de 2008].

PÉREZ, Pilar y GARRIDO, María (2006): “Antropología del periodismo. La observación no participante en una revista de alta gama", Comunicación y pluralismo, $\mathrm{n}^{\mathrm{o}}$ 1, Universidad Pontificia de Salamanca, pp. 99-125.

PERINAT, Adolfo y MARRADES, M. ${ }^{a}$ Isabel (1980): Mujer, prensa y sociedad en España: 1800-1939. Madrid, Centro de Investigaciones Sociológicas.

PLAZA, Juan (2005): Modelos de varón y mujer en las revistas femeninas para adolescentes. La representación de los famosos. Madrid, Fundamentos.

RECODER, M. ${ }^{a}$ José (1982): Revista Hola (1944-1979). Testimonios de historia, política y cultura. Tesina de licenciatura. Barcelona, Universidad Autónoma de Barcelona.

ROIG, Mercedes (1989): A través de la prensa, la mujer en la historia. Francia, Italia, España, S. XVIII-XX. Madrid, Ministerio de Asuntos Sociales.

SELVA, Marta y SEGURA, Isabel (1984): Revistes de dones 1846-1935. Barcelona, Edhasa.

SULLEROT, Evelyne (1963): La presse féminine. Paris, Armand Colin.

TORRES, Rosario (2007): "Revistas de moda y belleza: el contenido al servicio de la forma bella", Ámbitos, no 16, Universidad de Sevilla, pp. 213-225.

VÁZQUEZ, Manuel A. (1999): Mujer, ecología y comunicación en el nuevo horizonte planetario. Sevilla, Mergablum.

WARREN, Carl N. (1975): Géneros periodísticos informativos. Barcelona, ATE. 